\title{
Atividade gastroprotetora do extrato etanólico de Pavonia alnifolia A.St.-Hil.
}

\author{
EWALD, B.T.'; LOYOLLA, C.M.'; PEREIRA, A.C.H.'; LENZ, D.'; MEDEIROS, A.R.S2; ANDRADE, T.U.'; \\ NOGUEIRA, B.V. ${ }^{3}$; PEREIRA, T.M.C. ${ }^{1,2}$; ENDRINGER, D.C. ${ }^{1,2, *}$ \\ 'Núcleo de Pesquisa em Ciências Farmacêuticas, Universidade Vila Velha, Rua Comissário José Dantas de \\ Melo, $n^{\circ}$ 21, Vila Velha - ES, CEP 29102-770, Vila Velha, ES, Brasil. 'Instituto Federal de Educação, Ciência e \\ Tecnologia do Espírito Santo, Av. Min. Salgado Filho, 1000, Vila Velha-ES, 29106-345, Brasil. ${ }^{3}$ Universidade \\ Federal do Espírito Santo, Av. Marechal Campos, 1468, Vitória - ES, CEP 29.043-900, Brasil. *Autor para \\ correspondência: denise.endringer@uvv.br
}

RESUMO: No Brasil, a família Malvaceae está representada por aproximadamente 200 espécies e algumas foram descritas como gastroproteroras. Pavonia alnifolia A.St.-Hil. (Malvaceae) foi selecionada após uma abordagem quimiossistemática, considerando-se sua potencial capacidade em prevenir lesões gástricas. Assim, a atividade gastroprotetora do extrato etanólico de caules de $P$. alnifolia foi avaliada utilizando o modelo de indução aguda da lesão gástrica por etanol acidificado em camundongos. Além disso, foram quantificados o teor de flavonóides, pelo método de cloreto de alumínio, e de polifenóis, pelo método Folin-Ciocalteu, uma vez que a relação desses componentes com a proteção gástrica foi evidenciada. Os ensaios apontaram redução acentuada das lesões gástricas em camundongos tratados com o extrato da planta em todas as doses ensaiadas (10, 100 e $300 \mathrm{mg} / \mathrm{kg}$ ). Esse efeito pode estar relacionado com a presença de polifenóis, cujo teor encontrado foi $74,3 \pm 7,5 \mu \mathrm{g}$ equivalente de pirogalol $/ \mathrm{mg}$ do material vegetal examinado e $82,7 \pm 7,1 \mu \mathrm{g}$ equivalente de pirogalol /mg da amostra no extrato preparado por percolação e teor de flavonoides totais, que por sua vez apresentou um resultado de $17,1 \pm 1,4 \mu \mathrm{g} / \mathrm{mg}$ de extrato. $O$ extrato apresentou proteção da mucosa gástrica e este efeito pode estar relacionado à presença dos polifenóis e flavonóides encontrados.

Palavras-chave: Pavonia, Malvaceae, gastroproteção, flavonóides, polifenóis.

\begin{abstract}
Gastro protective activity of the Pavonia alnifolia A.St.-Hil. extract. In Brazil, the Malvaceae family is represented by at about 200 species. Some of those species are known as gastro protective ones. The Pavonia alnifolia A.St.-Hil (Malvaceae) was selected after a chemosystematic approach. The gastro preventive activity of the ethanol extract of stems Pavonia alnifolia was evaluated through the use of the Ethanol:chlroridric acid model on mice. The quantification of the total flavonoids (aluminum chloride method) and total polyphenols (Folin-Ciocalteu method) was also performed since the relation of those components with gastric protection has been previously highlighted. The tests showed a significant reduction of the ulcer formation in the mice treated with the plant extract $(10,100$ and $300 \mathrm{mg} / \mathrm{kg})$. This effect may be related to the presence of polyphenols whose content was found to be $74.3 \pm 7.5 \mu \mathrm{g} / \mathrm{mg}$ of vegetal material and $82.7 \pm 7.1 \mu \mathrm{g} / \mathrm{mg}$ of crude extract and flavonoids, which in turn showed a content of $17.1 \pm 1.4 \mu \mathrm{g} / \mathrm{mg}$ dry extract.
\end{abstract}

Keywords: Pavonia, Malvaceae, antiulcerogenic, flavonoids, polyphenols.

\section{INTRODUÇÃO}

A úlcera péptica é uma das principais doenças gastrintestinais Fatores como estresse, tabagismo, deficiência nutricional, agentes nocivos como álcool, anti-inflamatórios não esteróides (AINE) e infecção por Helicobacter pylori, podem levar ao desenvolvimento e formação das úlceras pépticas (Belaiche et al., 2002; Silva et al., 2010).
Pacientes acometidos por úlceras estão sujeitos a complicações em seu quadro clínico e, em casos extremos, até a morte (Leontiadis et al., 2005). Assim, o tratamento e a prevenção são importantes para a preservação da vida dos indivíduos. Existem diversos produtos farmacêuticos disponíveis para o tratamento da úlcera gástrica, por exemplo,

Recebido para publicação em 02/05/2013 
os antagonistas de receptores histamínicos, os inibidores da bomba de prótons, os antiácidos e os anticolinérgicos (Singh et al., 2008; Alimi et al., 2011). No entanto, a maioria destes fármacos disponíveis podem ocasionar reações adversas graves (Devi et al., 2007; Alimi et al., 2011). Diante do exposto, o estudo das plantas medicinais e suas aplicações pode ser uma alternativa na busca de um tratamento mais eficaz e com menos efeitos indesejáveis.

Diversos estudos evidenciaram a capacidade anti-ulcerogênica de algumas espécies vegetais (Andrade et al., 2007; Silva et al., 2010; Alimi et al., 2011). Na espécie Maytenus robusta (Celastraceae), o efeito antiulcerogênico foi atribuído, em parte, a presença de flavonóides em sua composição química (Andrade et al., 2007). As frações aquosa e butanólica da espécie Abarema cochliacarpos (Fabaceae) apresentaram atividade antiulcerogênica, assim esse efeito pode estar relacionado à presença de polifenóis, incluindo taninos (Silva et al., 2010). A atividade antiulcerogênica também foi atribuída à presença de substâncias fenólicas, flavonoides e sacarídeos presentes na espécie Opuntia ficus-indica (L.) Mill. (Cactaceae) Alimi et al. (2011).

Espécies da família Malvaceae foram descritas como gastroproteroras Gürbüz et al. (2003). A família Malvaceae está representada no Brasil por aproximadamente 754 espécies distribuídas em 69 gêneros (Bolvini et al., 2014). O gênero Pavonia (Malvaceae) compreende aproximadamente 135 espécies, no Brasil (Esteves, 2014).

O extrato etanólico de Pavonia alnifolia A.St.-Hil. (Malvaceae) apresentou atividade hipotensora e inibitória in vitro da enzima conversora de Andrade et al. (2012). A partir de uma abordagem quimiossistemática, a espécie $P$. alnifolia foi selecionada para análise quanto ao seu potencial biológico. $P$. alnifolia é uma das espécies que se encontra vulnerável à extinção, segundo a lista oficial da flora ameaçada no Espírito Santo (Brasil, 2005). O progresso das fronteiras agrícolas e o avanço dos setores produtivos são fatores que têm contribuído para a degradação do meio ambiente. Essas práticas têm ameaçado ecossistemas e, por conseguinte, a variabilidade de espécies, ocasionando a extinção das mesmas (Fachim \& Guarin, 1995). Dessa forma, muitas plantas podem ser extintas antes mesmo de terem seu potencial terapêutico avaliado.

O objetivo do presente estudo foi avaliar o extrato etanólico de caules de $P$. alnifolia quanto a sua atividade gastroprotetora no modelo in vivo de indução aguda por etanol acidificado

\section{MATERIAL E MÉTODO Material vegetal e extração}

Caules de Pavonia alnifolia A. St.-Hil. foram coletados em agosto de 2009, no Parque Estadual Paulo Cesar Vinha (protocolo número 629/09 permissão, IEMA). Uma exsicata foi depositada no Herbário da Universidade Federal do Espírito Santo, sendo identificada pela botânica Dra. Luciana Dias Thomaz (VIES 17.697). Após a secagem a $45^{\circ} \mathrm{C}$ por $72 \mathrm{~h}$, o material vegetal foi moído $(200,0 \mathrm{~g})$ e percolado com solução hidroetanólica $(80 \% \mathrm{v} / \mathrm{v})$. O solvente foi removido sob pressão reduzida fornecendo $69,0 \mathrm{~g}$ de um resíduo marrom. O extrato etanólico de caules de $P$. alnifolia (EPA) foi mantido em dessecador sob vácuo por pelo menos $48 \mathrm{~h}$ para a remoção completa do solvente. Alíquotas do extrato foram dissolvidas em solução salina, para ser usado em ensaios farmacológicos.

Para a quantificação do teor de polifenóis totais e flavonoides totais foram pesados, com precisão de $1,0 \mathrm{mg}$, cerca de $250,0 \mathrm{mg}$ do pó da droga vegetal. Ao extrato foram adicionados 10,0 $\mathrm{mL}$ de etanol, aquecendo-se a mistura à ebulição em chapa quente, e mantendo-se em banho-maria à temperatura de $80-90^{\circ} \mathrm{C}$ por $20 \mathrm{~min}$, seguidos de 10 min em ultrassom ( $40 \mathrm{~Hz}$ ). Resfriou-se em água corrente, deixou-se decantar o sedimento e filtrou-se através de papel de filtro qualitativo, transferiu-se para um balão volumétrico de $10 \mathrm{~mL}$, completandose o volume com etanol.

\section{Determinação de polifenóis totais}

O teor de polifenóis nos extratos da amostra foi determinado por meio do método de Folin-Ciocalteu, com adaptações (Purwantiningsih et al., 2011; Singleton \& Rossi, 1965). A curva de calibração foi preparada com solução de pirogalol (10 a $350 \mu \mathrm{g} / \mathrm{mL}$ ) e a quantificação dos polifenóis totais foi feita através da equação da reta da curva de calibração $y=1,1429 x+0,007$ e $r^{2}=0,9977$. Os resultados foram expressos como $\mu \mathrm{g}$ de equivalentes de pirogalol (EP) por grama de extrato seco ou droga vegetal seca. Todas as análises foram realizadas em triplicata.

\section{Determinação de flavonoides}

Para determinação do total de flavonoides foi utilizado o método colorimétrico de cloreto de alumínio (AICl ) (Zhishen et al., 1999; Marinova et al., 2005; El-Bẻltagi et al., 2007). A absorbância foi determinada em espectrofotômetro (T80+ UV/VIS Spectrometer PG instruments LTD) no comprimento de onda de $415 \mathrm{~nm}$. A curva de calibração foi preparada com soluções de rutina 31,25 a 1000 $\mu \mathrm{g} / \mathrm{mL}$. A quantificação de flavonoides totais foi determinada a partir da equação de regressão de calibração $y=0,0033 x+0,0121 e r^{2}=0,9991$. As 
análises foram realizadas em triplicata.

\section{Ensaio gastroprotetor}

Foram utilizados camundongos com peso entre $30-44 \mathrm{~g}$. Os animais foram deixados em jejum, em gaiolas anti-coprofagia por $24 \mathrm{~h}$, recebendo apenas solução de glicose a 10\% e água sem restrições. Os animais foram distribuídos randomicamente em sete grupos. A úlcera foi induzida por administração intragástrica de solução $150 \mathrm{mM}$ de ácido clorídrico $(\mathrm{HCl})$ em etanol $(\mathrm{EtOH})$ $95 \%$, sendo usado o volume de $5 \mathrm{~mL} / \mathrm{kg}$ (Mizui et al., 1987; Morimoto et al., 1994; Shujaa et al., 2009; Oyagi et al., 2010). Os animais do grupo 1 (controle positivo, $n=6$ ) sofreram indução de úlcera e após 1 hora foram eutanasiados com tiopental. Os grupos 2,3 e $4(n=6)$ receberam pré-tratamento oral com o extrato de $P$. alnifolia nas doses respectivas de 300 , 100 e $10 \mathrm{mg} / \mathrm{kg}$, preparados em solução salina. Uma hora após o tratamento receberam a solução de etanol acidificado para induzir a úlcera e após uma hora foram eutanasiados com o anestésico tiopental. O grupo $5(n=3-5)$ recebeu apenas o extrato de P.alnifolia na dose de $300 \mathrm{mg} / \mathrm{kg}$ para avaliar a gastrotoxicidade intrínseca. O sexto grupo $(n=5)$ recebeu apenas o veículo. O sétimo grupo recebeu pré-tratamento oral com o lanzoprazol $(3 \mathrm{mg} / \mathrm{kg}$ ), seguido da indução da lesão gástrica por etanol acidificado. O estômago dos animais foi retirado para a observação macroscópica de tamanho e aspecto das lesões, presença de hiperemia e perda de muco avaliado por escore $0,1,2,3$, sendo 0 para a perda total de muco, 1 para perda parcial de muco, 2 para a presença de muco, 3 para a presença de muco em abundância. $O$ conteúdo gástrico foi coletado e posteriormente foi titulado com solução padronizada de hidróxido de sódio $(\mathrm{NaOH}) 0,01 \mathrm{M}$ para determinação do $\mathrm{pH}$. O ensaio gastroprotetor foi realizado com a aprovação do Comitê de Ética da UVV (protocolo No150/2011 CEUA/UVV).

\section{Análise histológica}

Os estômagos dos animais foram abertos a partir da maior curvatura e conservados em solução de formol tamponado $10 \%$. Foram então processados para posterior emblocamento em parafina histológica. As amostras de tecido após emblocadas foram cortadas em secções de 2,5 $\mu \mathrm{m}$. Lâminas contendo cortes consecutivos foram preparadas com coloração de hematoxilina-eosina. As amostras foram analisadas em microscópio óptico Olympus AX70 com sistema de aquisição de imagens câmera Zeiss modelo AxioCam ERc5S.

\section{Análise estatística}

Os valores da avaliação biológica e das determinações químicas foram expressos como média \pm desvio padrão. A análise estatística dos dados foi realizada utilizando-se Análise de Variância de Uma Via (ANOVA), seguida pelo teste a posteriore de Tukey e para significância adotada foi $p<0,05$.

\section{RESULTADO E DISCUSSÃO}

O efeito preventivo do extrato etanólico de caules $P$. alnifolia na formação de úlceras por indução aguda por etanol acidificado foi avaliado em camundongos pela indução das lesões gástricas.

O grupo controle positivo (G1) recebeu apenas a etanol acidificado e apresentou intenso dano na mucosa, demonstrado pela perda de muco, que foi acentuada, assim como a hiperemia e pela presença de lesões na superfície da mucosa gástrica (Figura 1, G1). Na análise histológica, observou-se vasodilatação na mucosa e submucosa (Figura 2, Imagem A), acompanhada de infiltração de células inflamatórias e edema seguido de fragmentação do epitélio de superfície e das glândulas gástricas (Figura 2, Imagem C). Tais alterações são compatíveis com o descrito na literatura para esse tipo de lesão (Oyagi et al., 2010).

O grupo G6 recebeu somente o veículo e, conforme esperado, sua mucosa não apresentou dano significativo, uma vez que a perda de muco deste grupo foi discreta e a hiperemia não foi observada (Figura 1, G6). Dados que foram
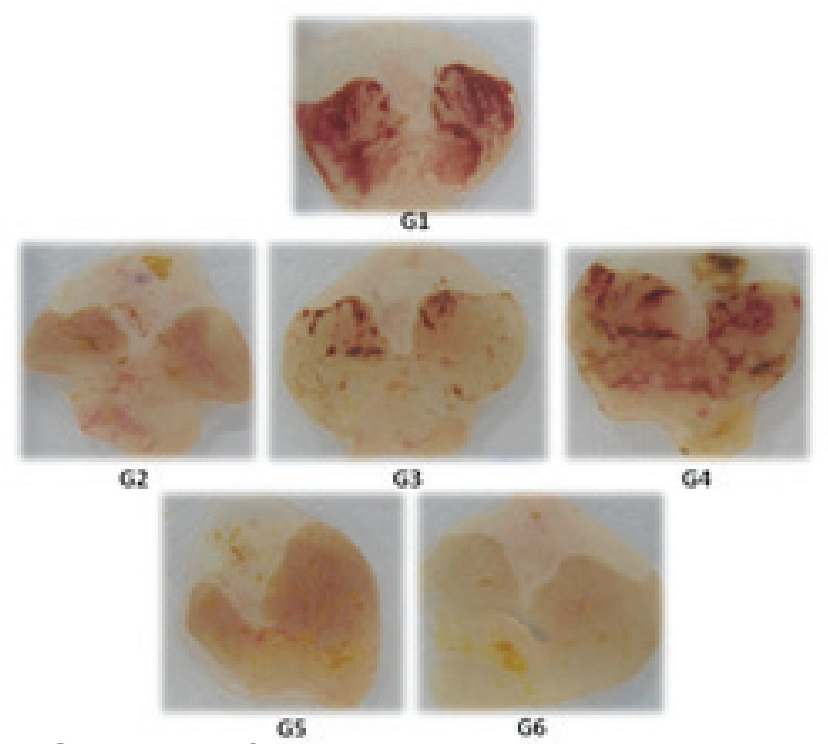

FIGURA 1. Efeito do extrato etanólico de caule de $P$. alnifolia no pré-tratamento de úlcera gástrica induzida por etanol e $\mathrm{HCl}$ em camundongos. $\mathrm{G} 1$ : etanol acidificado (5 mL/kg); G2, G3 e G4: extrato etanólico de caule de $P$. alnifolia, 300, 100 e 10 mg/ $\mathrm{kg}$, respectivamente, antes da indução das lesões; G5: extrato etanólico de caule de P. alnifolia, 300 $\mathrm{mg} / \mathrm{kg}$ para testar gastrotoxicidade e; G6:veículo, solução salina. 

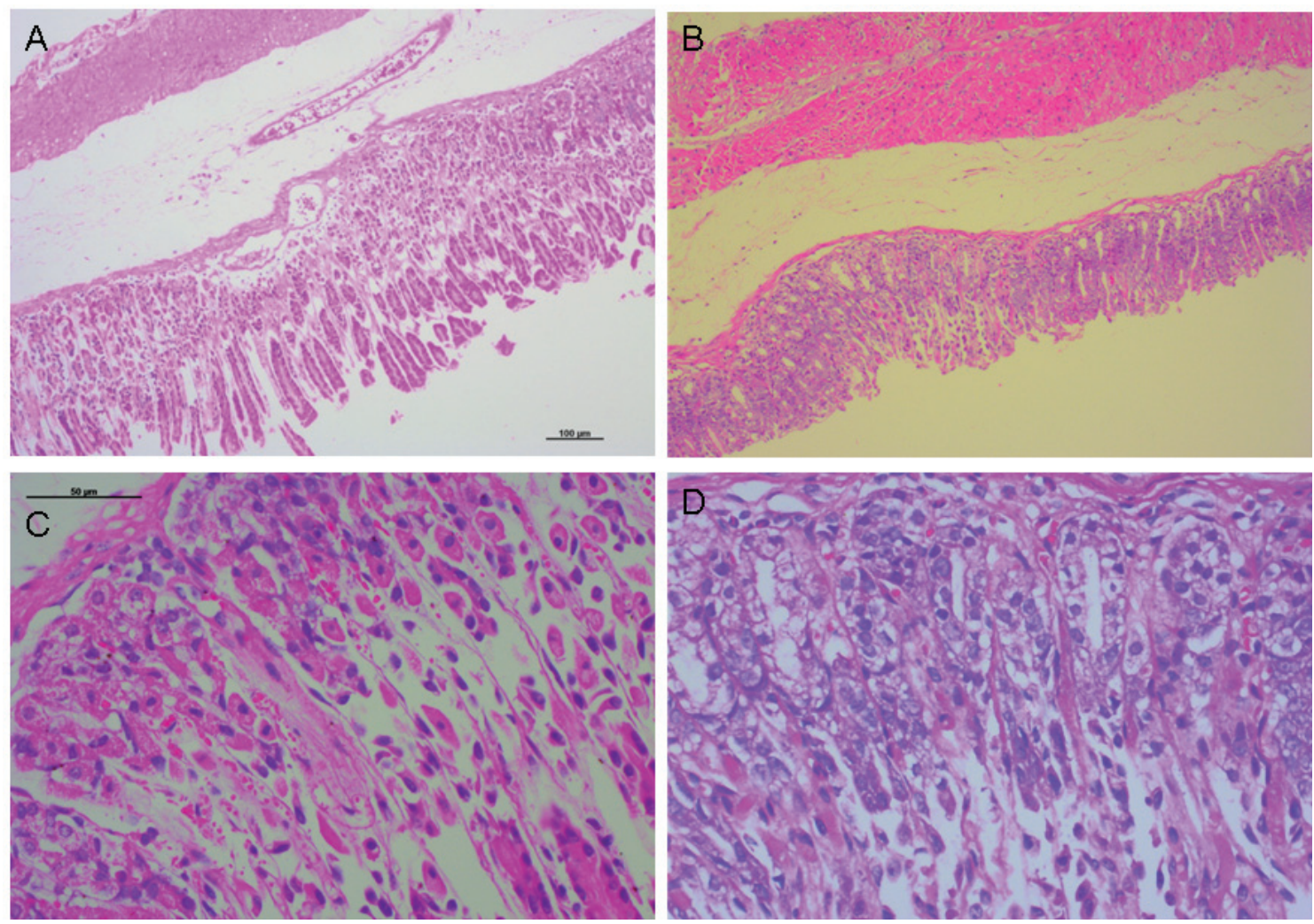

FIGURA 2. Fotomicrografias de estômagos corados com hematoxilina-eosina. (A e C) Imagens microscópicas de lesões induzidas por etanol/HCl sem nenhum tratamento prévio. (B e D) Imagens microscópicas de lesões pré-tratados com extrato etanólico de caule de $P$. alnifolia ( $300 \mathrm{mg} / \mathrm{kg}$ ). Escala: $100 \mu \mathrm{m}$ (micrografias superiores) e $50 \mu \mathrm{m}$ (micrografias inferiores).

confirmados na análise microscópica onde o tecido apresentava sua integridade preservada.

Os camundongos que receberam prétratamento com o extrato de $P$. alnifolia apresentaram um menor dano, tanto macroscopicamente quanto na análise histológica (Figura 2, Imagens B e D), quando comparado ao grupo controle positivo, evidenciando a proteção gástrica (Figura 1, G2 a G4 e Figura 3).

O conteúdo gástrico dos camundongos foi titulado e o $\mathrm{pH}$ desse conteúdo encontra-se expresso na tabela 1 . Os dados desse parâmetro

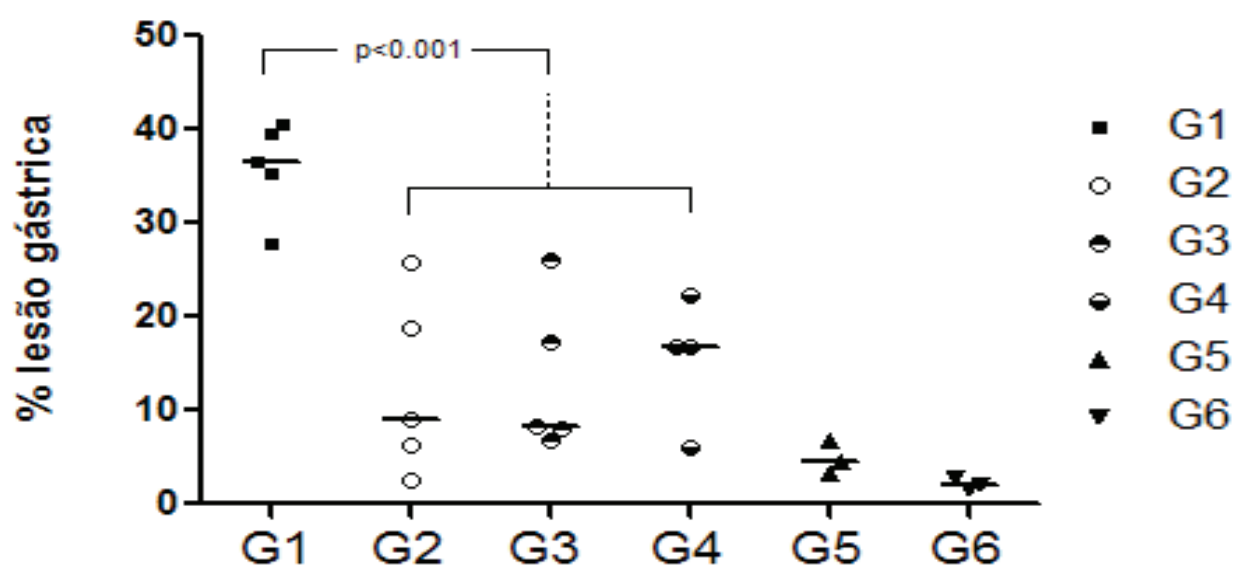

FIGURA 3. Inibição da formação de lesões gástricas pelo pré-tratamento com extrato etanólico de caule de $P$. alnifolia, 300, 100 e $10 \mathrm{mg} / \mathrm{kg}$, respectivamente G2, G3 e G4. A comparação estatística foi realizada utilizando ANOVA seguido pelo pós-teste de Tukey. O grupo sétimo não foi incluído na figura. 
TABELA 1. Alterações de $\mathrm{pH}$ e das lesões induzidas de acordo com o pré- tratamento com $P$. alnifolia em camundongos.

\begin{tabular}{|c|c|c|c|c|}
\hline Grupos & Pré-Tratamento & Dose & $\mathrm{pH}^{*}$ & Lesões Gástricas \% \\
\hline 1-Etanol-HCl & 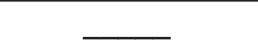 & 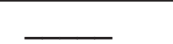 & 1,91 & $30 \pm 13,3^{c}$ \\
\hline 2-Etanol-HCl & Pavonia alnifolia & $300 \mathrm{mg} / \mathrm{kg}$ & 1,71 & $12,5 \pm 9,5^{b}$ \\
\hline 3-Etanol-HCl & Pavonia alnifolia & $100 \mathrm{mg} / \mathrm{kg}$ & 1,73 & $13,2 \pm 8,3^{b}$ \\
\hline 4-Etanol-HCl & Pavonia alnifolia & $10 \mathrm{mg} / \mathrm{kg}$ & 2,78 & $12,5 \pm 8,8^{b}$ \\
\hline 5-Etanol-HCl ${ }^{* *}$ & Pavonia alnifolia & $300 \mathrm{mg} / \mathrm{kg}$ & 2,97 & $4,8 \pm 1,8^{a}$ \\
\hline 6-Salina** & ـ & - & & $2,1 \pm 0,6^{a}$ \\
\hline 7-Etanol-HCl & Lanzoprazol & $3 \mathrm{mg} / \mathrm{kg}$ & 1,71 & $11,1 \pm 7,8^{b}$ \\
\hline
\end{tabular}

* Os valores expressos representam a média do grupo.

** Os grupos 5 e 6 não receberam etanol + HCl. O grupo 5 recebeu somente o extrato de P.alnifolia e o grupo 6 recebeu somente o veículo. Letras iguais na mesma coluna representam que não há diferença estatística.

indicam que efeito da planta não se deve à elevação do $\mathrm{pH}$, não sendo, portanto, semelhante ao mecanismo dos antiácidos. $\mathrm{O}$ pH da mucosa normal de camundongos é de aproximadamente três.

O etanol acidificado infiltra-se rapidamente na mucosa gástrica e causa danos à membrana, ocasionando a esfoliação de células, a erosão e a formação de úlceras (Oyagi et al., 2010). O mecanismo de indução de úlcera é mediado por espécies reativas de oxigênio (ROS) (Oyagi et al., 2010; Yadav et al., 2013). No extrato etanólico de $P$. alnifolia foi identificado a presença de rutina (Andrade et al., 2012), flavonoide com elevada capacidade antioxidante (Yang et al., 2008).

O teor de flavonoides foi determinado através da reação colorimétrica com $\mathrm{AlCl}_{3}$ (Funari \& Ferro, 2006). $O$ extrato etanólico de caule de $P$. alnifolia apresentou um teor de flavonoides totais 18 vezes maior $(17,1 \pm 1,4 \mu \mathrm{g} / \mathrm{mg}$ de extrato seco, quantificados em rutina), quando comparados com a droga vegetal $(0,9 \pm 0,0 \mu \mathrm{g} / \mathrm{mg}$ de droga vegetal, calculados em rutina), indicando eficiência do método de extração para flavonóides.

Os resultados obtidos na determinação dos polifenóis pelo método Folin- Ciocalteu foram expressos como $\mu \mathrm{g}$ de equivalentes de pirogalol (EP) por g de extrato bruto e por $\mathrm{g}$ da droga vegetal. O teor de polifenóis totais na droga vegetal foi de $74,3 \pm 7,5 \mu \mathrm{g} E P / \mathrm{mg}$ da droga vegetal e o extrato preparado por percolação apresentou um aumento na concentração destes constituintes, como esperado, o teor encontrado foi de $82,7 \pm 7,1 \mu \mathrm{g}$ $\mathrm{EP} / \mathrm{mg}$ da amostra.

Em países como o Brasil, onde há uma rica biodiversidade e parte da população com acesso restrito a medicamentos, as plantas medicinais são uma importante opção para o tratamento de diferentes enfermidades. O emprego de plantas medicinais ricas em flavonoides e polifenóis, como o extrato etanólico de $P$. alnifolia, pode ser uma alternativa eficaz e de baixa toxicidade para a prevenção de lesões gástricas conforme evidenciado nesse modelo experimental. Esse efeito pode estar relacionado aos flavonoides e polifenóis encontrados na amostra. Novos estudos são necessários para estabelecer os mecanismos desse efeito.

\section{AGRADECIMENTOS}

Agradecemos à UVV e a FUNADESP pelo suporte financeiro.

\section{REFERÊNCIAS}

ALIMI, H. et al. Evaluation of antioxidant and antiulcerogenic activities of Opuntia ficus indica $f$. inermis flowers extract in rats. Environmental Toxicology and Pharmacology, v.32, n.3, p.406-416, 2011.

ANDRADE, S.F. et al. Evaluation of the antiulcerogenic activity of Maytenus robusta (Celastraceae) in different experimental ulcer models. Journal of Ethnopharmacology, v.113, n.2, p.252-257, 2007.

ANDRADE, T.U. et al. Pavonia alnifolia A. ST. HIL.: In vivo hypotensive effect and in vitro ace inhibitory activity. International Journal of Pharmacy and Pharmaeutical Sciences, v.4, suppl.1, p.124-126, 2012.

BELAICHE, J. et al. Observational survey of NSAID-related upper gastro-intestinal adverse eventsin Belgium. Acta Gastroenterology Belgium, v.65, n.2, p.65-73, 2002. BOVINI, M.G.; ESTEVES, G.; DUARTE, M.C. Malvaceae in Lista de Espécies da Flora do Brasil. Jardim Botânico do Rio de Janeiro. Available in: <http://floradobrasil. jbrj.gov.br/jabot/floradobrasil/FB156>. Access on: 02 Mar. 2014.

BRASIL. Instituto Estadual de Meio Ambiente e Recursos Hídricos. Lista oficial da flora ameaçada de extinção no Espírito Santo. Espírito Santo (2005). Disponível em: http://www.meioambiente.es.gov.br/web/flora.htm. Acesso em 06 jun 2015.

DEVI, R.S. et al. Gastroprotective effect of Terminalia arjuna bark on diclofenac sodium induced gastric ulcer. 
Chemico-Biological Interactions, v.167, n.1, p.71-83, 2007.

EL-BELTAGI, H.S. et al. Evaluation of fatty acids profile and the content of some secondary metabolites in seeds of different flax cultivars (Linumus itatissimum L.). Plant Physiology, v.33, n.3-4, p.187-202, 2007.

ESTEVES, G. Pavonia in Lista de Espécies da Flora do Brasil. Jardim Botânico do Rio de Janeiro. Disponíve em: <http://floradobrasil.jbrj.gov.br/jabot/floradobrasil/ FB9118>. Access em 02 Mar. 2014.

FACHIM, E.; GUARIM, V.L.M.S. Guarim. Conservação da biodiversidade: espécies da flora de Mato Grosso. Acta BotanicaBrasilica, v.9, n.2, p.281-287, 1995.

FUNARI, C.S.; FERRO, V.O. Análise de própolis. Ciência e Tecnologia de Alimentos, v.26, n.1, p.171-178, 2006.

GÜRBÜZ, İ. et al. Anti-ulcerogenic activity of some plants used as folk remedy in Turkey. Journal of Ethnopharmacology, v.88, n.1, p.93-97, 2003.

LEONTIADIS, G. et al. Systematic review and metaanalysis of proton pump inhibitor therapy in peptic ulcer bleeding. British Medical Journal, v.330, p.68-75, 2005.

MARINOVA, D. et al. Total phenolics and total flavonoids in bulgarian fruits and vegetables. Journal of the University of Chemical Technology and Metallurgy, v.40, n.3, p.255-260, 2005.

MIZUI, T. et al. A possible mechanism of protection by polyamines against gastric damage induced by acidified ethanol in rats: polyamine protection may depend on its antiperoxidative properties. Journal of Physiology and Pharmacology, v.44, n.1, p.43-50, 1987.

MORIMOTO, Y. et al. Effects of KB-5492, a new anti-ulcer agent with a selective affinity for the sigma-receptor, on aspirin-induced disruption of the rat gastric mucosal barrier. Journal of Physiology and Pharmacology, v.64, n.1, p.49-55, 1994.
OYAGI, A. et al. Protective effects of a gastrointestinal agent containing Korean red ginseng on gastric ulcer models in mice. Complementary and Alternative Medicine, v.10, p.45, 2010.

PURWANTININGSIH, S. et al. Free radical scavenging activity of the standardized ethanolic extract of Eurycoma longifolia (TAF-273). International Journal of Pharmacy and Pharmaceutical Sciences, v.3, n.4, p.343-347, 2011.

SHUJAA, N. et al. Analysis of the effect of neuropeptides and cannabinoids in gastric mucosal defense initiated centrally in the rat. Journal of Physiology and Pharmacology, v.60, suppl.7, p.93-100, 2009.

SILVA, M.S.et al. Abaremacochliacarpos: Gastroprotective and ulcer-healing activities. Journal of Ethnopharmacology, v.132, n.1, p.134-142, 2010.

SINGH, S. et al.The gastric ulcer protective effect of boswellic acids, a leukotriene inhibitor from Boswellia serrata, in rats. Phytomedicine, v.15, n.6-7, p.408415, 2008

SINGLETON, V.L.; ROSSI JR, J.A. Colorimetry of total phenolics with phosphomolybdic-phosphotungstic acid reagents. American Journal of Enology and Viticulture, v.16, n.3, p.144-158, 1965.

YADAV, S.K. et al. Inhibition of TNF- $\alpha$, and NF-KB and JNK pathways accounts for the prophylactic action of the natural phenolic, allylpyrocatechol against indomethacin gastropathy. Biochimica et Biophysica Acta, v. 1830, n. 6, p. 3776-2786, 2013.

YANG, J.; GUO, J.;YUAN, J. In vitro antioxidant properties of rutin. LWT - Food Science and Technology, v.41, n. 6, p. 1060-1066, 2008.

ZHISHEN, J. et al. The determination of flavonoid contents in mulberry and their scavenging effects on superoxide radicals. Food Chemistry, v.64, n.4, p.555-559, 1999. 